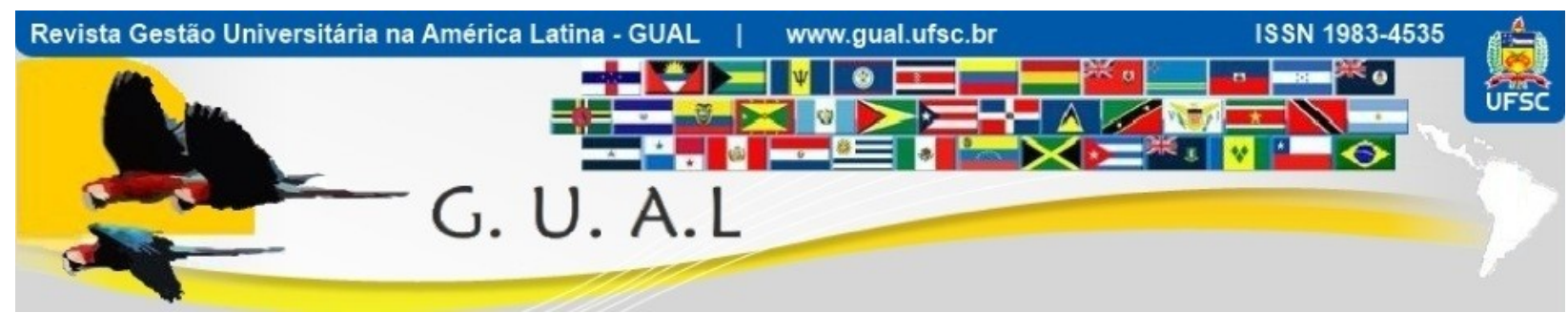

DOI: http://dx.doi.org/10.5007/1983-4535.2015v8n2p1

\title{
DEFINIÇÃO DE PAINEL DE INDICADORES DE DESEMPENHO PARA INSTITUIÇÕES COMUNITÁRIAS DE ENSINO SUPERIOR
}

\section{DEFINITION OF PANEL PERFORMANCE INDICATORS FOR COMMUNITY INSTITUTIONS OF HIGHER EDUCATION}

\begin{abstract}
Antonio Zanin, Doutor Universidade Comunitária da Região de Chapecó - UNOCHAPECÓ zanin@unochapeco.edu.br

Odilon Luiz Poli, Doutor Universidade Comunitária da Região de Chapecó - UNOCHAPECÓ odilon@unochapeco.edu.br

Geovanne Dias de Moura, Doutor Universidade Comunitária da Região de Chapecó - UNOCHAPECÓ geomoura@terra.com.br

Carlos Fernando Jung, Doutor Faculdades Integradas de Taquara - FACCAT carlosfernandojung@,gmail.com

Carla Schwengber ten Caten, Doutora Universidade Federal do Rio Grande do Sul - UFRGS tencaten@producao.ufrgs.br
\end{abstract}

Recebido em 28/setembro/2014

Aprovado em 13/abril/2015

Sistema de Avaliação: Double Blind Review

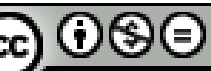

Esta obra está sob uma Licença Creative Commons Atribuição-Uso. 


\title{
RESUMO
}

O estudo objetiva desenvolver um painel de indicadores de desempenho para auxiliar no processo de gestão das instituições comunitárias de ensino superior. Este estudo está baseado em uma abordagem qualitativa e quantitativa, utilizando grupo focal com gestores de uma IES comunitária, no sentido de propor um conjunto de indicadores elencados dentro de 4 (quatro) constructos: (I) Ensino; (II) Pesquisa; (III) Extensão; (IV) Gestão. A avaliação do grau de importância dos indicadores propostos no painel ocorreu por meio de aplicação de questionário a 9 (nove) gestores de IES comunitárias, sendo 3 (três) pertencentes ao Sistema ACAFE; 2 (duas) de IES associadas ao COMUNG; e 4 (quatro) confessionais. Estabeleceu-se como ponto de corte, os indicadores que atingiram uma média inferior a 3,5, excluindo-se do painel 4 indicadores. A principal contribuição deste estudo é a elaboração de um painel de indicadores de desempenho com 118 indicadores associados a 4 (quatro) constructos e 14 (quatorze) sub-constructos, podendo ser aplicado em Instituições de Ensino Superior comunitárias, alinhando ao planejamento estratégico de longo prazo.

Palavras-Chaves: Avaliação de desempenho. Indicadores de desempenho. IES Comunitárias.

\begin{abstract}
The study aims to develop a dashboard of performance indicators to assist in the management process of the Community institutions of higher education. This study is based on a qualitative and quantitative approach, using focus group with managers of a Community IES, to propose a set of indicators listed within four (4) constructs: (i) Education; (II) Research; (III) Extension; (IV) administration. The assessment of the importance of the proposed indicators on the panel was through a questionnaire to nine (9) Community HEI managers, three (3) belonging to ACAFE System; Two (2) associated with IES COMUNG; and four (4) confessional. It was established as the cutoff point, the indicators that achieved an average of less than 3,5, were established as the cutting point, excluding 4 indicators from the panel. The main contribution of this thesis, is a panel of performance indicators with 118 indicators associated with four (4) dimensions and fourteen (14) sub - dimensions, which can be applied to higher education community institutions, aligning them to the strategic planning long term.
\end{abstract}

Keywords: Performance Evaluation. Performance indicators. Community IES. 


\section{INTRODUÇÃO}

A oferta de Ensino Superior no Brasil vem crescendo ano a ano. Consequentemente, a competitividade acirrada existente nos demais setores da economia passou a afetar, também, a educação. No setor educacional, o número de Instituições de Ensino Superior (IES) aumentou 44,4\% no período de 2002 a 2011, ou seja, de 1.637 IES em 2002, para 2.365 em 2011. Do total, em 2011, 12\% são públicas e 88\% são consideradas privadas (INEP, 2012).

Cabe ressaltar que as IES consideradas comunitárias estão classificadas como IES privadas. Esse conceito, na verdade, engloba uma diversidade de modelos institucionais, incluindo desde instituições confessionais, instituições criadas e mantidas por fundações privadas e até instituições criadas pelo poder público, mantidas por fundações de origem pública, mas geridas por direito privado. Em comum, possuem o direcionamento para a atuação comunitária e o caráter filantrópico sem fins lucrativos.

No mesmo período de 2002 a 2011, as IES públicas cresceram 45,5\% e as IES privadas 44,3\% (INEP, 2012). Essa realidade impõe a necessidade de um planejamento estratégico mais apurado, principalmente no caso das IES privadas, que dependem da cobrança de mensalidades dos estudantes para manterem-se no mercado. Portanto, tal como em vários outros setores, é necessário que as Instituições Privadas de Ensino Superior (IPES) despertem para as mudanças decorrentes da crescente globalização da economia, tal como ocorre em outros segmentos (RODRIGUES FILHO; OLIVEIRA, 2011).

Sendo assim, os gestores precisam formar instituições organizadas e com visão de futuro (BRAGA, 2004), pois somente àquelas que forem mais bem administradas, que estiverem voltadas ao mercado ao qual servem e que utilizarem-se de práticas modernas de gestão serão capazes de sobreviver e prosperar (CARVALHO, 1997). Nesse sentido, gerenciar estrategicamente uma Universidade, de acordo com Rivero e Lópes (2012) significa: a) elaborar o seu desenvolvimento futuro, cientes das condições turbulentas existentes no ambiente, tentando avaliar as mudanças que ocorrem e ir ao encontro (sistema aberto); b) priorizar os fatores externos com relação aos internos, dando importância também nos principais usuários de resultados institucionais e parceiros estratégicos que podem apoiar a missão; c) assumir atitudes proativas, empreendedoras e criativas, com uma abordagem baseada no futuro e mais realista; e d) estar consciente de que não basta desenhar a projeção estratégica institucional, também é importante torná-la realidade por meio de ações que 
promovam mudanças, ou enfrentar a resistência interna, que é um sistema que integra a concepção, implementação e complementação da estratégia.

Para tanto, é preciso conhecer os fatores que afetam o processo de avaliação institucional nas universidades, diagnosticando o ambiente interno e externo, servindo de base para o PDI, e por consequência, ao planejamento estratégico. Rodrigues (2003) cita que a avaliação se constitui em uma ferramenta de melhoria, mas sua utilidade está condicionada aos processos de tomada de decisão. Díaz (1995) observa que, quando não existem políticas para assegurar a qualidade dentro das instituições, é muito difícil que as informações provenientes das avaliações possam ser utilizadas para tomar decisões.

No caso das IES, para se fazer uma avaliação, é preciso conhecer profundamente os elementos que configuram sua estrutura, pois existem as particularidades e diferenciais próprios de cada organização. Não é possível um conhecimento da totalidade institucional sem o conhecimento prévio das partes que integram essa estrutura e as formas como elas interagem entre si (RODRIGUES, 2003). É preciso considerar ainda o Sistema Nacional de Avaliação da Educação Superior (SINAES) e os parâmetros por ele definidos, visto que esse sistema define a ação dos avaliadores e impõe parâmetros de qualidade às instituições.

Nesse sentido, torna-se necessário a implantação de indicadores de desempenho que monitorem os objetivos propostos, tendo metas estabelecidas. Esses indicadores não podem ficar restritos ao financeiro, devem englobar também as questões não financeiras, pois, segundo Lima (2003), indicadores somente financeiros não conseguem demonstrar aos gestores o "quanto" da estratégia estava sendo implantada e "quais" os aspectos dessa estratégia não estariam atingindo os resultados previamente almejados.

Diante deste contexto, acredita-se que o processo avaliativo em instituições de ensino superior comunitárias precisa se adaptar às mudanças observadas no cenário brasileiro, ambiente com crescimento significativo de instituições públicas, além de instituições privadas que são adquiridas por grandes consolidadores que se colocam no mercado com preços agressivos, o que requer um aprimoramento da avaliação das dimensões ensino (graduação e pós-graduação), pesquisa, extensão e gestão.

Para tanto, considera-se fundamental o debate sobre como conduzir o processo de avaliação e, mais importante, como utilizar os resultados da avaliação no planejamento institucional (RODRIGUES, 2003). Diante do exposto, o objetivo geral deste estudo é propor 
um painel de indicadores de desempenho para auxiliar no processo de gestão de instituições de ensino superior comunitárias.

O estudo é relevante, pois segundo Rodrigues (2003), a avaliação institucional tem sido tema obrigatório em qualquer reflexão que se faça em âmbito universitário. Além disso, analisar universidades comunitárias é importante, haja vista que possuem grande dependência das mensalidades, dificuldades para acessar recursos públicos, qualificação deficiente do corpo docente, evasão escolar, pesquisa incipiente, alta concentração de cursos noturnos, salas de aula superlotadas e proliferação de cursos de baixo custo operacional (LIMA, 2003), e em alguns casos, falta de profissionalização da gestão. Fatores que justificam a importância de indicadores de desempenho para essas instituições.

\section{INSTITUIÇÕES DE ENSINO SUPERIOR COMUNITÁRIAS}

O Brasil conta com cerca de 2.365 instituições de ensino superior, dentre as quais: $84,7 \%$ são faculdades, $8 \%$ universidades, $5,6 \%$ centros universitários e 1,7\% representam os institutos federais de educação, ciência e tecnologia (IFs) e centros federais de educação tecnológica (CEFETs), de acordo com o Instituto Nacional de Estudos e Pesquisas - INEP (2013).

No que se refere à categoria administrativa, as IES podem ser públicas ou privadas. Dentre estas, $88 \%$ das IES de todo o país são privadas, incluindo-se as comunitárias, sendo que os $12 \%$ restantes, estão divididos em federal com 4,3\%, estadual com 4,7\% e municipal com apenas 3\%. Os números confirmam a carência no país no que se refere à educação pública mantida pelo Estado, fato que exige um desembolso financeiro de grande parte da população brasileira na busca de qualificação profissional. Em âmbito geral tem-se 284 IES públicas e 2.081 privadas, incluindo-se nestas, as comunitárias e confessionais.

As IES privadas ainda podem ter ou não fins lucrativos. As que não possuem fins lucrativos podem ser caracterizadas como comunitárias, confessionais e filantrópicas, conforme Brasil (1996):

I - particulares em sentido estrito, assim entendidas as que são instituídas e mantidas por uma ou mais pessoas físicas ou jurídicas de direito privado que não apresentem as características dos incisos abaixo;

II - comunitárias, assim entendidas as que são instituídas por grupos de pessoas físicas ou por uma ou mais pessoas jurídicas, inclusive cooperativas educacionais, sem fins lucrativos, que incluam na sua entidade mantenedora representantes da comunidade; (Redação dada pela Lei nº 12.020, de 2009); 
III - confessionais, assim entendidas as que são instituídas por grupos de pessoas físicas ou por uma ou mais pessoas jurídicas que atendem à orientação confessional e ideologias específicas e ao disposto no inciso anterior;

IV - filantrópicas, na forma da lei.

No que se refere à gestão das universidades públicas, Pessoa (2000 p.37) cita que "sua gestão tem sido permeada de dificuldades, abrangendo desde a escassez de recursos, à rigidez da estrutura administrativa". O autor ainda comenta que a utilização dos recursos está sob as regras do Tribunal de Contas e a autonomia administrativa dos gestores é muito restrita.

Com relação à gestão das universidades comunitárias Lopes (2004) cita ser diferente da gestão de uma universidade estatal ou de outro tipo de universidade privada, pois a dinâmica baseia-se em princípios estratégicos, tais como: sustentabilidade, efetividade social e complementaridade.

Lopes (2004, p. 114) afirma que: “[...] a sustentabilidade é o que define a natureza jurídica da Universidade comunitária. Para o autor (2004, p. 114) “o orçamento é elaborado por uma instituição que mantém financeiramente a Universidade, seu ente mantido. $\mathrm{Na}$ verdade, uma Universidade comunitária é composta de dois entes, que se completam: o mantenedor e o mantido; um é o jurídico; outro, o acadêmico". Lopes (2004, p. 114) esclarece que "o mantenedor lida com a estrutura de provimento e sustentação; o mantido, com a estrutura acadêmica; ambos interligados pela interferência do Reitor”.

No que se refere à efetividade e a complementaridade, Lopes (2004, p. 114) cita ser "princípios que exigem do Reitor esforço de avaliação e replanejamento diários, tornando-o um líder sintonizado com a dinâmica interna e externa da comunidade”. O autor ainda comenta que em uma Universidade estatal a receita orçamentária provém dos cofres públicos, já na Universidade comunitária o Reitor é o responsável pela receita, fazendo-as acontecer, projetando a segurança financeira e econômica da gestão. Nesse caso, é fundamental a utilização de indicadores de desempenho na gestão, visando monitorar as ações tomadas e planejar estratégias futuras.

\section{INDICADORES DE DESEMPENHO}

A utilização de indicadores de desempenho, conforme Martins (2004, p. 1), “[...] relaciona-se diretamente com a entrega de valor ao cliente e com o desempenho global da organização, alinhando e permitindo melhorar os propósitos de todas as pessoas afetadas pelos negócios". O autor (2004, p.1) complementa ainda, descrevendo que "os indicadores 
são ferramentas centrais por permitirem um acompanhamento das principais variáveis de interesse da empresa e por possibilitar o planejamento de ações visando melhorias de desempenho".

Nesse sentido, para Rodrigues et al. (2003), o sistema de indicadores das empresas deveriam ser planejados visando todos os aspectos relevantes para a gestão, para garantir sua coerência, bem como sua perfeita adequação aos interesses da organização. Pois, muitas entidades não utilizam nenhum sistema formal de indicadores, outras utilizam poucos indicadores e muitas têm indicadores em demasia, o que dificulta sua análise.

Os indicadores de desempenho, de acordo com Fischmann e Zilber (2000, p. 1), são “[...] instrumentos capazes de auxiliar na definição do planejamento estratégico e na consequente determinação das estratégias empresariais". Os autores destacam ainda que indicadores “[...] permitem verificar a propriedade com que as decisões foram tomadas e, eventualmente, corrigir e readequar o processo vigente de gestão".

Sem indicadores de desempenho apropriados, os gerentes não podem avaliar o desempenho de sua organização, ou comparar sua performance com a de seus competidores (DAVIS et al., 2001). Deste modo, Paula e Ichikawa (2002, p. 1) citam que "ter indicadores é como ter instrumentos de planejamento, gerenciamento e controle dos processos das organizações". Holanda (2007, p. 30), menciona que "os indicadores de desempenho fazem parte do sistema de gerenciamento da performance empresarial. E são informações qualitativas e quantitativas que permitem avaliar o desempenho da empresa e seus objetivos".

Morissete (1977) classifica os indicadores de desempenho em indicadores financeiros e não financeiros, descrevendo que indicador financeiro é uma medida quantitativa, expressa em valor monetário, resultante das ações tomadas pelas empresas, e cita como exemplos o lucro e o retorno sobre os investimentos; já o indicador não financeiro é uma medida quantitativa que não será expressa em valor monetário, ou seja, é apresentado em uma métrica diferente de uma unidade monetária, e cita como exemplos a participação no mercado e evolução do volume de produção.

As medidas não financeiras, para Banker et. al. (2000), são melhores indicadores de desempenho futuro do que as financeiras, pois auxiliam os administradores a focarem suas ações em perspectivas de longo prazo. Nesse sentido, Kaplan e Norton (1997) descrevem que os indicadores financeiros são inadequados para orientar e avaliar a trajetória da empresa em 
um ambiente competitivo, pois não fornecem orientações adequadas para as ações de curto prazo para criar valor financeiro futuro.

Para Costa (2003), os indicadores podem ser classificados em: a) indicadores primários que controlam e monitoram processos críticos da empresa, e que precisam ser disponibilizados para a organização como um todo e as informações auxiliam na tomada de decisão estratégica e gerencial; b) indicadores secundários que controlam ou monitoram processos de apoio da empresa e o conteúdo das informações interessa apenas às pessoas que estão diretamente ligadas ao processo a ser medido.

Oliveira et al. (1995) classificam os indicadores de desempenho em indicadores estratégicos ou gerenciais que são utilizados com a intenção de impulsionar a implantação de estratégias; e indicadores operacionais que são indicadores estabelecidos com o objetivo de acompanhar as tarefas desenvolvidas dentro do processo, devendo ser coerente com as estratégias dimensionadas pela empresa.

\section{PROCEDIMENTOS METODOLÓGICOS}

Para atender ao objetivo proposto no artigo, realizou-se pesquisa exploratória, bibliográfica e abordagem qualitativa e quantitativa. A construção do painel de indicadores de desempenho foi baseada principalmente em teses e artigos científicos. Inicialmente, identificaram-se diversos indicadores que foram agrupados em quatro constructos: (I) Ensino; (II) Pesquisa; (III) Extensão; (IV) Gestão.

Além dos quatro constructos, foi adotada uma classificação com sub-constructos, ou seja: (I) Ensino: graduação, identificando-se 18 indicadores. Pós-graduação lato sensu com 4 indicadores, e, pós-graduação stricto sensu, também com 4 indicadores. O constructo (II) Pesquisa foi dividido em dois sub-constructos. Grupos de pesquisa com 4 indicadores relacionados, e, programas de stricto sensu tendo 3 indicadores. Para Extensão (III), identificou-se o sub-constructo: programas, projetos e atividades de extensão, relacionando 4 indicadores. Por fim, o constructo (IV) Gestão, foi dividido em 8 sub-constructos: gestão acadêmica com um indicador selecionado; Equilíbrio econômico e financeiro, 11 indicadores; 2 indicadores no sub-constructo comunicação com a sociedade; Instrumentos de avaliação 3 indicadores; Clima organizacional 2 indicadores; desenvolvimento humano 15 indicadores; procedimentos acadêmicos/processos internos 5 indicadores, e, conhecimento e inovação com 6 indicadores. 
Após a identificação destes indicadores foi organizado um grupo focal com gestores de uma IES comunitária, no sentido de incluir indicadores não identificados na etapa inicial, ou então excluir indicadores que fossem considerados desnecessários. O grupo focal ocorreu em 12 de fevereiro de 2014 com a participação de oito pessoas, funcionários de uma Universidade Comunitária: Reitor; Vice-Reitora de Ensino, Pesquisa e Extensão; Vice-Reitor de Planejamento e Desenvolvimento; Diretora de Ensino; Diretor de Planejamento e Desenvolvimento; Diretora de Ensino; Diretor de Planejamento e Controle; Diretor Contábil Financeiro; Contador e, Coordenadora do Setor de Planejamento.

Ao iniciar a reunião, o pesquisador, também mediador do grupo focal, informou que a reunião seria gravada para facilitar a transcrição das falas do grupo. Após uma explanação dos objetivos da pesquisa, sugeriu-se que as pessoas se manifestassem sobre quais indicadores seriam importantes para a avaliação de Instituições de ensino superior comunitárias. Para que houvesse uma maior contribuição à pesquisa, os indicadores apurados por meio da literatura não foram expostos aos membros participantes do grupo focal.

No grupo focal surgiram novos indicadores para todos os constructos e que foram adotados: (I) Ensino, 5 indicadores; (III) Extensão 3 indicadores. O constructo (IV), Gestão, foi o que obteve maior número de indicadores sugeridos, totalizando 30 . Na discussão do grupo focal, não apareceram novos indicadores para o constructo (II) Pesquisa.

Em seguida, para descaracterizar um estudo de caso específico de uma IES, levando-se em conta que o modelo poderá ser aplicado às demais IES comunitárias, a validação foi efetuada por diversos gestores de IES comunitárias. Assim sendo, os indicadores que permaneceram no quadro após o grupo focal, fizeram parte do modelo que passou pela avaliação dos gestores de IES comunitárias, concluindo o painel de avaliação de desempenho.

A avaliação do modelo ocorreu por meio da aplicação de um questionário que continha informações sobre os constructos e sub-constructos em que os indicadores estavam lotados. Tal questionário foi encaminhado para os gestores de IES comunitárias. Solicitou-se aos respondentes que avaliassem cada indicador, de acordo com o grau de importância quanto à sua aplicabilidade nas IES Comunitárias. A escala likert permitiu atribuir nota de $1 \mathrm{a} 5$, sendo 1 sem importância; 2 pouco importante; 3 indiferente; 4 importante e 5 muito importante.

Foram consideradas IES Comunitárias aquelas que constavam em alguma das seguintes categorias, de acordo com a iniciativa de criação: (I) Fundacionais: Refere-se ao 
modelo catarinense, pertencentes à ACAFE, as quais foram criadas por Lei Municipal ou Estadual; (II) Comunitárias/Laicas: Tiveram como origem a comunidade e/ou sociedade civil de uma cidade ou região, tendo como exemplo as IES pertencentes ao COMUNG (modelo gaúcho), dentre outras estabelecidas em várias regiões do Brasil; (III) Confessionais: Possuem origem em entidades religiosas.

Para validar o modelo, projetou-se uma amostra mínima de 6 (seis) IES Comunitárias, sendo 2 (duas) de cada modelo: fundacional (modelo ACAFE), comunitárias (modelo COMUNG) e confessionais. Nesse sentido, encaminhou-se o questionário de forma aleatória para aproximadamente 20 (vinte) IES Comunitárias dos três segmentos. Obteve-se um retorno de 3 (três) questionários respondidos de gestores de IES fundacionais (ACAFE); 2 (duas) Comunitárias associadas ao COMUNG e 4 (quatro) confessionais. Os modelos de IES Comunitárias existentes (fundacionais, comunitárias e confessionais) possuem características semelhantes. No entanto entendeu-se que a análise por segmento/modelo, traz informações mais uniformes entre os respondentes. Os respondentes atribuíram notas de 1 a 5 , de acordo com a aplicabilidade em IES Comunitárias, sendo 1 sem importância e 5 muito importante.

\section{DESCRIÇÃO E ANÁLISE DOS RESULTADOS}

Esta seção contém a descrição e a análise dos dados coletados. Inicialmente, estabeleceu-se como ponto de corte, os indicadores avaliados que obtiveram média inferior a 3,5, estes foram excluídos do modelo proposto. Para facilitar a análise, também separou-se os indicadores por constructo e sub-constructos. O Quadro 1 apresenta as médias do constructo ensino, sub-constructo graduação. 


\begin{tabular}{|c|c|c|c|c|c|c|c|c|}
\hline & & & & & VSTITUIÇÕ & & & \\
\hline & & INDICADORES & DESCRIÇÃO & ACAFE & $\begin{array}{l}\text { COMUNG } \\
\text { MÉDIA }\end{array}$ & CONFEC & GERAL & PADRÃO \\
\hline \multirow{10}{*}{ 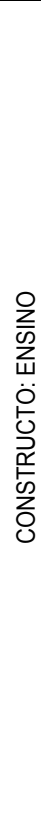 } & \multirow{10}{*}{ 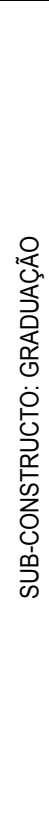 } & $\mathrm{Cl}$ igual ou superior a 4 & $\begin{array}{l}\text { Obtenção de conceito institucional } \\
\text { (Cl) igual ou superior a } 4 \\
\text { estabelecido pelo MEC }\end{array}$ & 4,7 & 4,5 & 4,75 & 4,6 & 0,4714 \\
\hline & & IGC igual ou superior a 4 & $\begin{array}{c}\text { Obtenção de Indice Geral de Cursos } \\
\text { (IGC) com nota igual ou superior a } 4 \\
\text { em todos os cursos avaliados pelo } \\
\text { MEC }\end{array}$ & 4,3 & 4,5 & 4,75 & 4,5 & 0,6849 \\
\hline & & $\begin{array}{l}\text { Cursos reconhecidos ou em } \\
\text { reconhecimento }\end{array}$ & $\begin{array}{l}\text { Mínimo de } 60 \% \text { reconhecidos ou em } \\
\text { fase de reconhecimento }\end{array}$ & 4,3 & 5,0 & 4 & 4,4 & 1,0541 \\
\hline & & $\begin{array}{l}\text { Número de estudantes } \\
\text { matriculados }\end{array}$ & $\begin{array}{l}\text { Número total de estudantes } \\
\text { matriculados na graduação, pós- } \\
\text { graduação lato e stricto sensu, } \\
\text { extensão em EAD }\end{array}$ & 4,7 & 4,5 & 4,5 & 4,6 & 0,4969 \\
\hline & & $\begin{array}{c}\text { Número de estudante por } \\
\text { turma }\end{array}$ & $\begin{array}{l}\text { Média do número de estudantes por } \\
\text { turma }\end{array}$ & 5,0 & 4,5 & 4,25 & 4,6 & 0,4969 \\
\hline & & Estudantes/n. curso & $\begin{array}{l}\text { Média do número de estudantes por } \\
\text { total de cursos }\end{array}$ & 4,0 & 4,0 & 3,25 & 3,8 & 1,1547 \\
\hline & & Docentes/n. cursos & $\begin{array}{l}\text { Média do número de docentes por } \\
\text { total de cursos }\end{array}$ & 4,0 & 4,0 & 3,5 & 3,8 & 1,2273 \\
\hline & & Estudantes/docentes & $\begin{array}{l}\text { Média do número total de estudantes } \\
\text { por total de docentes }\end{array}$ & 4,3 & 4,0 & 4 & 4,1 & 0,7370 \\
\hline & & Estudantes/docentes $\mathrm{TI}$ & $\begin{array}{c}\text { Média do número total de estudantes } \\
\text { por total de docentes em Tempo } \\
\text { Integral (TI) }\end{array}$ & 3,3 & 4,5 & 4,25 & 4,0 & 0,6667 \\
\hline & & $\begin{array}{l}\text { Trancamentos, desistências } \\
\text { e cancelamentos }\end{array}$ & $\begin{array}{l}\text { \% de trancamentos, desistências e } \\
\text { cancelamentos em relação ao } \\
\text { número total de estudantes }\end{array}$ & 4,7 & 4,0 & 4,75 & 4,5 & 0,6849 \\
\hline
\end{tabular}

Quadro 1 Indicadores Ensino Graduação (i)

Fonte: Autor

Efetuando-se a análise do Quadro 1, percebe-se que não houve grandes disparidades entre os respondentes dos três segmentos de IES Comunitárias pesquisadas, o que pode ser verificado por meio do desvio padrão, apresentado na última coluna do quadro, exceto para o indicadores cursos reconhecidos ou em reconhecimento; estudantes/n.Curso; docentes/n.Cursos; avaliação ensino-aprendizagem e, número de estudantes que realizam estágios obrigatórios que apresentam desvio padrão acima de 1 . O ensino de graduação tem sido a atividade principal das IES, sendo que os indicadores foram bem avaliados.

Das IES da ACAFE, a menor média dentre os indicadores constantes no Quadro 36, ficou com o indicador "estudantes/docentes TI" com média 3,3, sendo este indicador pontuado em 4,5 nas IES do COMUNG e 4,25 entre as confessionais. Entre as IES do COMUNG, 4 (quatro) indicadores tiveram média 4 (quatro), considerando todos os indicadores em importante e muito importante. Estes indicadores possuem média similar às IES da ACAFE e Confessionais. De modo geral, a média dos indicadores relacionados ao ensino de graduação, dentre as IES confessionais, Quadro 1, ficaram entre importante e muito importante. Seguindo a análise de indicadores relacionados ao ensino de graduação apresentase o Quadro 2. 


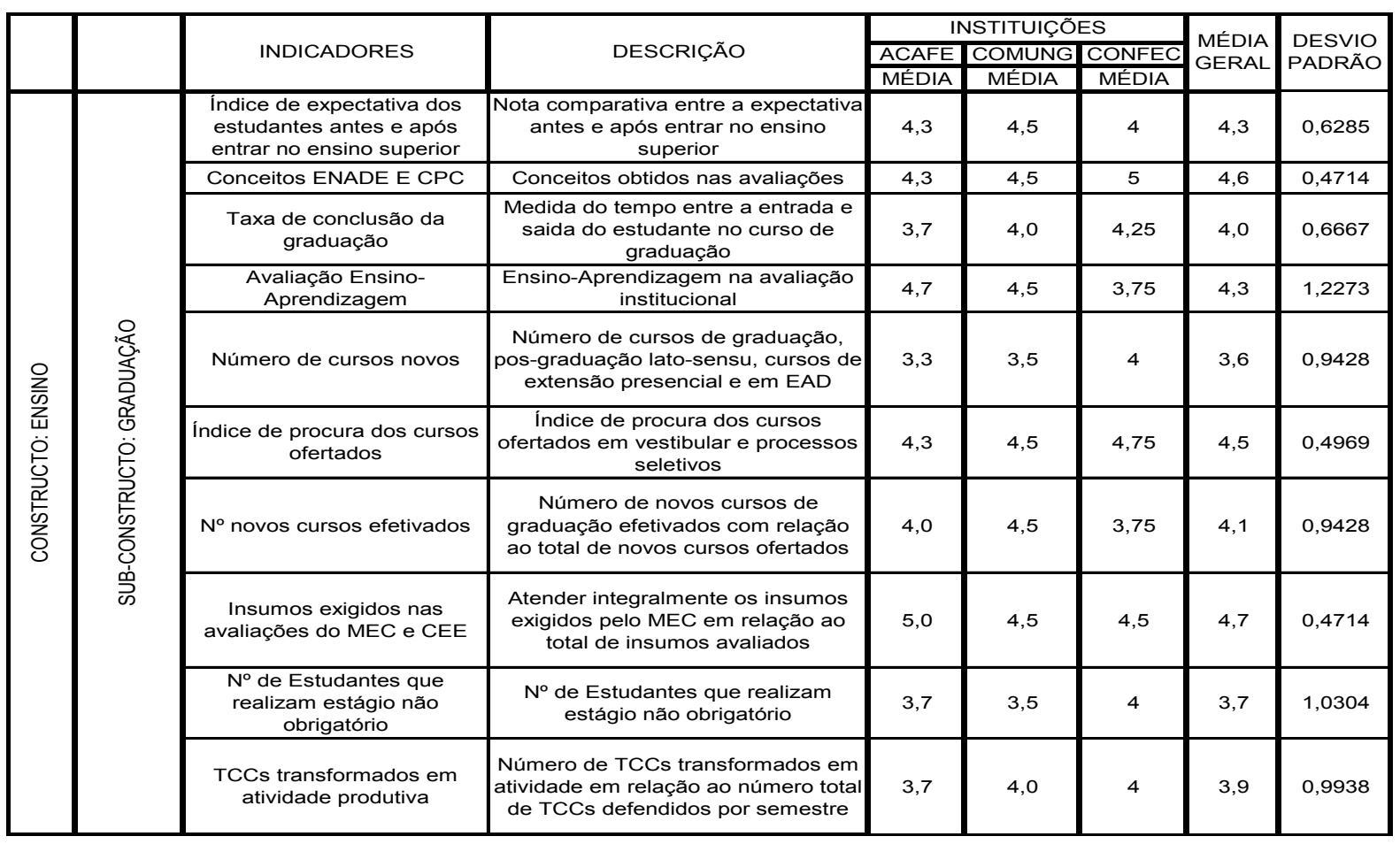

Quadro 2 Indicadores Ensino Graduação (ii)

Fonte: Autor

Visualiza-se no Quadro 2 que, na média das IES pertencentes à ACAFE, 4 (quatro) indicadores obtiveram média inferior a 4 (quatro). Tanto o segmento COMUNG quanto confessionais tiveram apenas 2 (dois) indicadores com média abaixo de 4 (quatro).

Embora o indicador "taxa de conclusão da graduação" foi considerado importante para as IES COMUNG e Confessionais, obtendo média 4,0 e 4,25 respectivamente, no segmento ACAFE apresentou média de 3,7. Da mesma forma, o indicador "TCCs transformados em atividade produtiva" obteve média de 3,7 na ACAFE, e 4 nos demais segmentos. No segmento confessionais, os indicadores "avaliação ensino-aprendizagem" e "número de cursos novos" foram avaliados com média inferior a 4, representando 3,75.

Dos 20 (vinte) indicadores elencados no constructo ensino, sub-constructo graduação, 15 apresentaram média geral acima de 4 (importantes), e 5 (cinco) com média entre 3,6 a 3,9, considerando-se todos os indicadores como importantes, motivo pelo qual foram mantidos. Por meio do Quadro 3, pode-se visualizar os indicadores relacionados ao constructo ensino, sub-constructo pós graduação lato-sensu. 


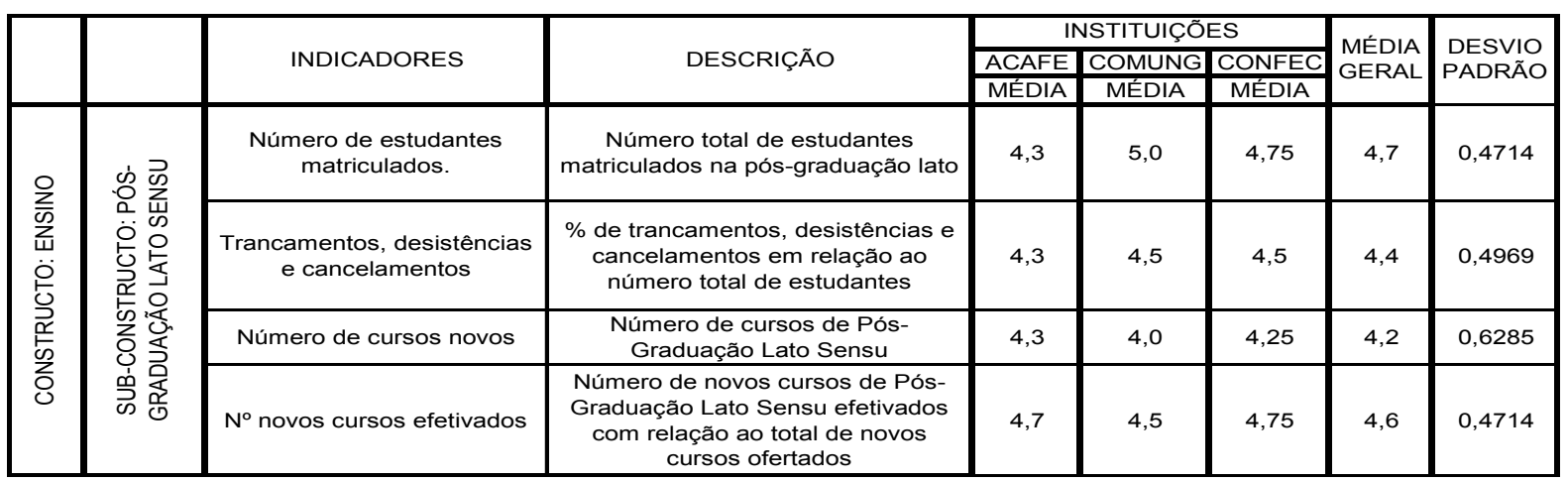

Quadro 1 Indicadores ensino pós-graduação lato-sensu

Fonte: Autor

Percebe-se no Quadro 3 que todos os 4 (quatro) indicadores foram avaliados como importantes por todos os respondentes. As médias são similares para os três segmentos. O indicador "número de estudantes matriculados" foi o que apresentou maior diferença, sendo 4,3 para os respondentes da ACAFE e 5,0 para o segmento COMUNG. O desvio padrão também não apontou diferença significativa entre todos os respondentes, não apresentando grandes variações. Ainda dentro do constructo ensino, elencou-se indicadores para o subconstructo pós-graduação stricto-sensu, conforme apresentado no Quadro 4.

\begin{tabular}{|c|c|c|c|c|c|c|c|c|}
\hline & & \multirow{3}{*}{ INDICADORES } & \multirow{3}{*}{ DESCRIÇÃO } & \multicolumn{3}{|c|}{ INSTITUIÇÕES } & \multirow{3}{*}{$\begin{array}{l}\text { MÉDIA } \\
\text { GERAL }\end{array}$} & \multirow{3}{*}{$\begin{array}{l}\text { DESVIO } \\
\text { PADRÃC }\end{array}$} \\
\hline & & & & ACAFE & COMUNG & CONFEC & & \\
\hline & & & & MÉDIA & MÉDIA & MÉDIA & & \\
\hline \multirow{7}{*}{ 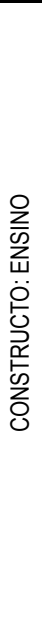 } & \multirow{7}{*}{ 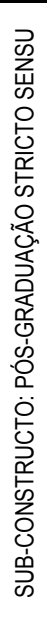 } & $\begin{array}{l}\text { Número de estudantes } \\
\text { matriculados }\end{array}$ & $\begin{array}{l}\text { Número total de estudantes } \\
\text { matriculados no Stricto Sensu. }\end{array}$ & 4,0 & 4,0 & 4,5 & 4,2 & 0,7857 \\
\hline & & Estudantes/docentes TI & $\begin{array}{c}\text { Média do número total de estudantes } \\
\text { por total de docentes em Tempo } \\
\text { Integral }(\mathrm{TI})\end{array}$ & 5,0 & 3,5 & 4,75 & 4,4 & 0,9558 \\
\hline & & $\begin{array}{c}\text { Trancamentos, desistências } \\
\text { e cancelamentos }\end{array}$ & $\begin{array}{l}\text { \% de trancamentos, desistências e } \\
\text { cancelamentos em relação ao } \\
\text { número total de estudantes }\end{array}$ & 4,7 & 3,5 & 4,75 & 4,3 & 0,9558 \\
\hline & & $N^{\circ}$ novos cursos efetivados & $\begin{array}{c}\text { Número de novos cursos de Pós- } \\
\text { Graduação Stricto Sensu efetivados } \\
\text { com relação ao total de novos } \\
\text { cursos ofertados }\end{array}$ & 3,3 & 3,5 & 3,5 & 3,4 & 1,3426 \\
\hline & & $\begin{array}{c}N^{\circ} \text { de participações em } \\
\text { congressos, seminários, } \\
\text { entre outros }\end{array}$ & $\begin{array}{l}\% \text { de docentes que participam de } \\
\text { congressos, seminários po período }\end{array}$ & 3,7 & 4,5 & 4 & 4,1 & 0,6667 \\
\hline & & $\begin{array}{l}N^{\circ} \text { de participações docentes } \\
\text { em bancas externas (redes) }\end{array}$ & $\begin{array}{c}\% \text { de docentes que participam de } \\
\text { bancas externas/semestre }\end{array}$ & 3,0 & 4,0 & 4 & 3,7 & 0,8165 \\
\hline & & $\begin{array}{c}\text { Docentes e discentes em } \\
\text { processos de } \\
\text { internacionalização }\end{array}$ & $\begin{array}{l}\mathrm{N}^{\circ} \text { de docentes e discentes em } \\
\text { processos de internacionalização }\end{array}$ & 3,3 & 4,5 & 4,5 & 4,1 & 0,7370 \\
\hline
\end{tabular}

Quadro 2 Indicadores ensino pós-graduação stricto-sensu Fonte: Autor

Verifica-se no Quadro 4, com base nas respostas dos gestores das IES pertencentes ao sistema ACAFE, 4 (quatro) indicadores com média inferior a 4. As IES confessionais atribuíram uma maior importância para esses indicadores, em relação às IES do sistema 
ACAFE e COMUNG, obtendo a maior média. No entanto, o indicador "número de novos cursos efetivados" não foi considerado importante pelos respondentes, obtendo-se média entre 3,3 e 3,5 nos três segmentos, com média geral 3,4. Esse mesmo indicador, apresentou um desvio padrão superior a 1 . Pela linha de conte estabelecido em 3,5, esse indicador deverá ser suprimido do painel, pois a média geral ficou em 3,4.

Desta forma, tomando-se como referência as médias gerais de cada indicador, optouse por excluir o indicador número de novos cursos efetuados, submetido para avaliação dentro do constructo ensino, sub-constructo pós-graduação stricto-sensu.

O constructo pesquisa, sub-constructo núcleo de iniciação científica, por meio do grupo focal, sugeriu 4 (quatro) indicadores, conforme apresentado no Quadro 5.

\begin{tabular}{|c|c|c|c|c|c|c|c|c|}
\hline & & \multirow{3}{*}{ INDICADORES } & \multirow{3}{*}{ DESCRIÇÃO } & \multicolumn{3}{|c|}{ INSTITUIÇÕES } & \multirow{3}{*}{$\begin{array}{l}\text { MÉDIA } \\
\text { GERAL }\end{array}$} & \multirow{3}{*}{$\begin{array}{l}\text { DESVIO } \\
\text { PADRÃO }\end{array}$} \\
\hline & & & & ACAFE & COMUNG & CONFEC & & \\
\hline & & & & MÉDIA & MÉDIA & MÉDIA & & \\
\hline \multirow{4}{*}{ 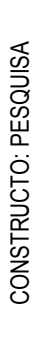 } & \multirow{4}{*}{ 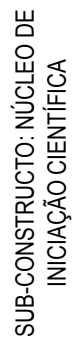 } & $\begin{array}{c}N^{\circ} \text { de projetos financiados e } \\
\text { não financiados/professor- } \\
\text { pesquisador }\end{array}$ & $\begin{array}{l}N^{\circ} \text { de projetos financiados e não } \\
\text { financiados/professor-pesquisador }\end{array}$ & 4,3 & 5,0 & 4,25 & 4,5 & 0,6849 \\
\hline & & $\begin{array}{l}\text { \% de professores envolvidos } \\
\text { em projetos de pesquisa }\end{array}$ & $\begin{array}{l}\% \text { de professores envolvidos em } \\
\text { projetos de pesquisa }\end{array}$ & 3,3 & 4,5 & 4,25 & 4,0 & 0,8165 \\
\hline & & $\begin{array}{l}\mathrm{N}^{\circ} \text { de estudantes/ bolsistas } \\
\text { envolvidos nos projetos }\end{array}$ & $\begin{array}{l}N^{\circ} \text { de estudantes/ bolsistas } \\
\text { envolvidos nos projetos }\end{array}$ & 4,0 & 4,0 & 4,25 & 4,1 & 0,7370 \\
\hline & & $\begin{array}{c}\text { Carga horária dos } \\
\text { pesquisadores dedicada a } \\
\text { projetos }\end{array}$ & $\begin{array}{c}\text { Carga horária dos pesquisadores } \\
\text { dedicada a projetos }\end{array}$ & 3,0 & 4,0 & 3,75 & 3,6 & 1,0657 \\
\hline
\end{tabular}

Quadro 5 Indicadores pesquisa: grupos de pesquisa Fonte: Autor

Por meio do Quadro 40, verifica-se que o indicador "carga horária dos pesquisadores dedicados a projetos", das IES do sistema ACAFE, foi considerado indiferente, com média 3,0. Este indicador foi o que obteve menor média entre todos os respondentes, pois entre as confessionais obteve 3,75 , ocasionando um desvio padrão acima de um Também o indicador "percentual de professores envolvidos em projetos de pesquisa ficou com média 3,3, entre as IES da ACAFE, não sendo considerado importante.. Em geral, embora com pequena margem de diferença, as IES associadas ao COMUNG atribuíram maior importância para o subconstructo analisado, ficando bem próximo as IES confessionais.

Dentro do constructo pesquisa, optou-se por criar o sub-constructo programas de stricto-sensu, local em que ocorre um maior volume de pesquisas. O Quadro 6 demonstra o resultado da avaliação dos indicadores propostos, referente ao pós-graduação stricto sensu. 


\begin{tabular}{|c|c|c|c|c|c|c|c|c|}
\hline & & \multirow{3}{*}{ INDICADORES } & \multirow{3}{*}{ DESCRIÇÃO } & \multicolumn{3}{|c|}{ INSTITUIÇÕES } & \multirow{3}{*}{$\begin{array}{l}\text { MÉDIA } \\
\text { GERAL }\end{array}$} & \multirow{3}{*}{$\begin{array}{l}\text { DESVIO } \\
\text { PADRÃO }\end{array}$} \\
\hline & & & & ACAFE & COMUNG & CONFEC & & \\
\hline & & & & MÉDIA & MÉDIA & MÉDIA & & \\
\hline \multirow{4}{*}{ 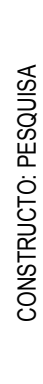 } & \multirow{4}{*}{ 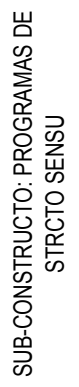 } & $\begin{array}{l}\text { Número de artigos } \\
\text { publicados. }\end{array}$ & $\begin{array}{l}\text { Número de publicações em } \\
\text { periódicos }\end{array}$ & 4,7 & 5,0 & 4,5 & 4,7 & 0,4714 \\
\hline & & $\begin{array}{c}\text { Conceito dos programas de } \\
\text { mestrados }\end{array}$ & $\begin{array}{l}\text { Atingir as notas exigidas para } \\
\text { manutenção dos programas }\end{array}$ & 5,0 & 4,5 & 4,25 & 4,6 & 0,4969 \\
\hline & & Produtividade docente & $N^{\circ}$ de artigos publicados/docente & 4,3 & 4,5 & 4,5 & 4,4 & 0,6849 \\
\hline & & $\begin{array}{l}\text { Produção científica em } \\
\text { relação ao número de } \\
\text { docentes e discentes }\end{array}$ & $\begin{array}{l}\text { \% de produção científica em relação } \\
\text { ao total de discentes e docentes nos } \\
\text { programas }\end{array}$ & 4,3 & 4,0 & 4,5 & 4,3 & 0,6667 \\
\hline
\end{tabular}

Quadro 6 Indicadores pesquisa: programas stricto-sensu Fonte: Autor

O Quadro 41 evidencia os resultados da pesquisa sobre a dimensão ensino, sub-eixo programas de stricto-sensu. Nota-se que 4 (quatro) indicadores foram submetidos para avaliação dos respondentes, sendo que todos os indicadores foram avaliados como importante e/ou muito importante. Dentro do sub-constructo analisado, as IES do COMUNG atribuíram melhor média entre os demais segmentos. A menor média foi o indicador "número de artigos publicados em periódicos" entre os respondentes de IES confessionais, ficando com média de 3,75. Percebe-se por meio do desvio padrão que não houve uma discrepância entre as respostas.

O constructo extensão, foi classificado em apenas um sub-constructo, ou seja: programas, projetos e atividades de extensão, tendo 8 (oito) indicadores, conforme se verifica no Quadro 7.

\begin{tabular}{|c|c|c|c|c|c|c|c|c|}
\hline & & \multirow[b]{2}{*}{ INDICADORES } & \multirow{2}{*}{ DESCRIÇÃO } & \multicolumn{3}{|c|}{ INSTITUIÇÕES } & \multirow{2}{*}{$\begin{array}{l}\text { MÉDIA } \\
\text { GERAL }\end{array}$} & \multirow{2}{*}{$\begin{array}{l}\text { DESVIO } \\
\text { PADRÃO }\end{array}$} \\
\hline & & & & $\frac{\text { ACAFE }}{\text { MÉDIA }}$ & $\frac{\text { COMUNG }}{\text { MÉDIA }}$ & $\frac{\text { CONFEC }}{\text { MÉDIA }}$ & & \\
\hline \multirow{8}{*}{ 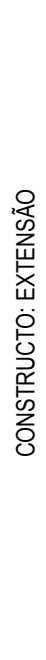 } & \multirow{8}{*}{ 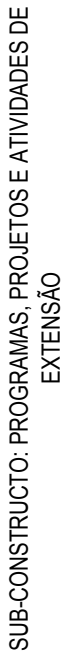 } & $\mathrm{N}^{\circ}$ novos cursos efetivados & $\begin{array}{l}N^{\circ} \text { de novos cursos de Extensão } \\
\text { efetivados com relação ao total de } \\
\text { novos cursos ofertados }\end{array}$ & 4,7 & 5,0 & 4,5 & 4,7 & 0,4714 \\
\hline & & $\begin{array}{c}N^{\circ} \text { de eventos/cursos de } \\
\text { extensão ofertados a } \\
\text { comunidade }\end{array}$ & $N^{\circ}$ de eventos/cursos & 4,3 & 4,5 & 4,25 & 4,4 & 0,6667 \\
\hline & & $\begin{array}{c}\mathrm{N}^{\circ} \text { de eventos e curso de } \\
\text { extensão efetivados com } \\
\text { recursos da assistência } \\
\text { social }\end{array}$ & $\mathrm{N}^{\circ}$ de eventos/cursos & 4,0 & 3,5 & 4 & 3,8 & 0,8749 \\
\hline & & $\begin{array}{c}\text { No de eventos de extensão } \\
\text { voltados à inserção } \\
\text { comunitária }\end{array}$ & $\mathrm{N}^{\circ}$ de eventos/cursos & 4,0 & 4,5 & 4,5 & 4,3 & 0,4714 \\
\hline & & $\begin{array}{c}N^{\circ} \text { de publicações divulgados } \\
\text { na imprensa }\end{array}$ & $\begin{array}{c}\text { No de publicações divulgados na } \\
\text { imprensa }\end{array}$ & 4,3 & 3,5 & 3,5 & 3,8 & 1,1331 \\
\hline & & $\begin{array}{c}N^{\circ} \text { de estudantes que atuam } \\
\text { como monitores com bolsa } \\
\text { de extensão }\end{array}$ & $\begin{array}{l}\mathrm{N}^{\circ} \text { de estudantes que atuam como } \\
\text { monitores com bolsa de extensão }\end{array}$ & 4,0 & 3,5 & 4,25 & 3,9 & 1,1547 \\
\hline & & $\begin{array}{l}\text { Carga horária destinadas à } \\
\text { extensão }\end{array}$ & $\begin{array}{l}\text { \% de carga horária destinadas à } \\
\text { extensão por docente }\end{array}$ & 3,7 & 4,0 & 3,5 & 3,7 & 1,1547 \\
\hline & & $\begin{array}{c}\text { Receita captada via projetos } \\
\text { de extensão }\end{array}$ & $\begin{array}{l}\text { Volume de recursos }(\mathrm{R} \$ \text { ) captados } \\
\text { advindos de projetos de extensão }\end{array}$ & 5,0 & 5,0 & 4,5 & 4,8 & 0,6285 \\
\hline
\end{tabular}

Quadro 7 Indicadores extensão: programas, projetos e atividades de extensão Fonte: Autor 
Verifica-se que $50 \%$ dos indicadores obtiveram média geral inferior a 4 (quatro). $\mathrm{O}$ indicador "carga horária destinada à extensão" que apresentou a menor média, 3,7, no geral, obteve 3,7 nas IES do sistema ACAFE e 3,5 nas confessionais, não sendo considerado importante. O indicador "número de publicações divulgados na imprensa" também foram avaliadas como não importante para as IES do COMUNG e confessionais, com média 3,5. No entanto, todos os indicadores serão mantidos, pois na média geral, nenhum ficou com média abaixo da linha de corte que foi definido em 3,5.

Os demais indicadores do sub-constructo programas, projetos e atividades de extensão permaneceram com média semelhante entre os três segmentos. O constructo gestão, é o que possui maior número de sub-constructos, totalizando 8 (oito). O Quadro 8 , demonstra os indicadores do constructo gestão sub-constructo gestão acadêmica.

\begin{tabular}{|c|c|c|c|c|c|c|c|c|}
\hline & & \multirow{3}{*}{ INDICADORES } & \multirow{3}{*}{ DESCRIÇÃO } & \multicolumn{3}{|c|}{ INSTITUIÇÕES } & \multirow{3}{*}{$\begin{array}{l}\text { MÉDIA } \\
\text { GERAL }\end{array}$} & \multirow{3}{*}{$\begin{array}{l}\text { DESVIO } \\
\text { PADRÃO }\end{array}$} \\
\hline & & & & ACAFE & COMUNG & CONFEC & & \\
\hline & & & & MÉDIA & MÉDIA & MÉDIA & & \\
\hline \multirow{8}{*}{ 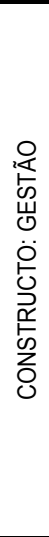 } & \multirow{8}{*}{ 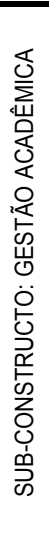 } & $\begin{array}{c}\text { Corpo Docente em regime de } \\
\text { tempo integral }\end{array}$ & $\begin{array}{c}\mathrm{N}^{\circ} \text { de docentes integrais em relação } \\
\text { ao total de docentes }\end{array}$ & 4,7 & 5,0 & 4,75 & 4,8 & 0,4157 \\
\hline & & Titulação Docente & $\begin{array}{c}\mathrm{N}^{\circ} \text { de docentes doutores, mestres e } \\
\text { especialistas }\end{array}$ & 4,7 & 5,0 & 4,75 & 4,8 & 0,4157 \\
\hline & & $\%$ de estudante/docente & $\begin{array}{c}\% \text { de estudante por docente em } \\
\text { tempo integral }\end{array}$ & 4,0 & 4,5 & 4,25 & 4,3 & 0,6285 \\
\hline & & $\begin{array}{l}\text { Tempo de experiência em } \\
\text { docência no ensino superior }\end{array}$ & $\begin{array}{c}\text { Tempo de experiência em docência } \\
\text { no ensino superior }\end{array}$ & 2,7 & 4,0 & 4,25 & 3,6 & 0,9428 \\
\hline & & $\begin{array}{l}\mathrm{N}^{\circ} \text { de componentes } \\
\text { curriculares/ docente }\end{array}$ & $\begin{array}{c}\mathrm{N}^{\circ} \text { de componentes curriculares de } \\
\text { atuação por docente }\end{array}$ & 3,0 & 4,5 & 4 & 3,8 & 1,0304 \\
\hline & & $\begin{array}{c}\text { Cumprimento de horários de } \\
\text { aula } \\
\end{array}$ & $\begin{array}{l}\% \text { de turmas que cumprem os } \\
\text { horários de aula/docente }\end{array}$ & 4,3 & 4,0 & 3,75 & 4,0 & 1,3333 \\
\hline & & $\begin{array}{l}\text { Índice de atualização dos } \\
\text { projetos pedagógicos de } \\
\text { curso }\end{array}$ & $\begin{array}{c}\% \text { de projetos pedagógicos } \\
\text { atualizados/ano }\end{array}$ & 4,0 & 4,5 & 3,75 & 4,1 & 1,1547 \\
\hline & & Cumprimento de caga horária & $\begin{array}{c}\% \text { de docentes que cumprem carga } \\
\text { horária }\end{array}$ & 4,3 & 4,5 & 3,75 & 4,2 & 1,2862 \\
\hline
\end{tabular}

Quadro 8 Indicadores gestão acadêmica Fonte: Autor

Por meio do Quadro 8, verifica-se que as melhores médias surgiram por meio dos respondentes pertencentes ao COMUNG, seguido das confessionais. $\mathrm{O}$ indicador com menor média 2,7, pouco importante, refere-se ao indicador "tempo de experiência em docência no ensino superior", no segmento ACAFE.

Esse mesmo indicador foi considerado importante pelos respondentes dos outros segmentos pesquisados, elevando a média geral para 3,6, permanecendo no painel, pois ficou com nota superior à nota de corte que é de 3,5. O mesmo ocorreu com o indicador "número de componentes curriculares/docente, que obteve média 3,0 no sistema ACAFE, 4,5 no COMUNG, e, 4,0 nas confessionais. Os demais indicadores foram avaliados como importante 
e muito importante por todos os respondentes. Destaca-se que houve discrepância entre os pesos atribuídos aos indicadores pelos respondentes. Na sequência, o Quadro 9, subconstructo comunicação com a sociedade, evidencia 2 (dois) indicadores.

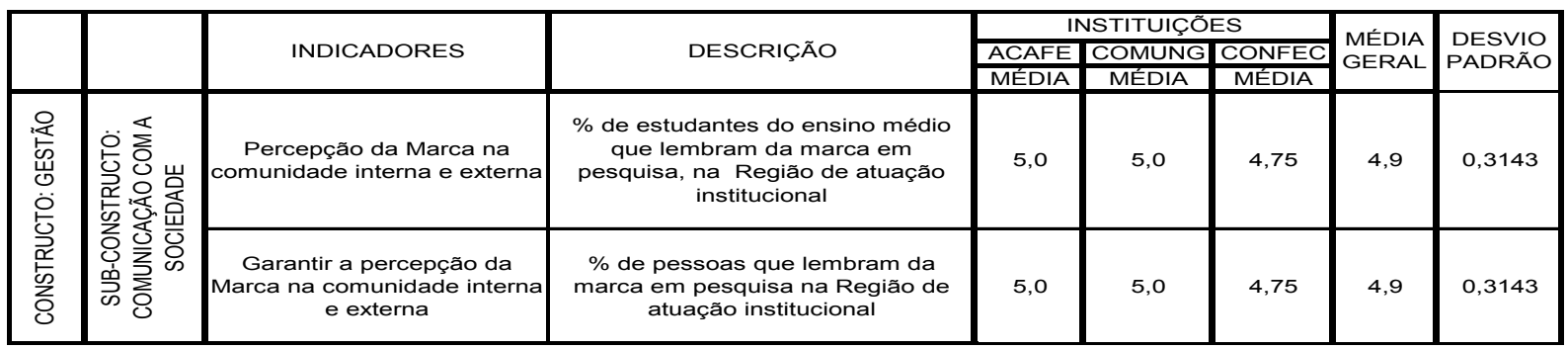

Quadro 9 Indicadores comunicação com a sociedade Fonte: Autor

Verifica-se no Quadro 9 que a média geral de cada indicador somou 4,9, considerados muito importante por todas as IES comunitárias pesquisadas. No sistema ACAFE e COMUNG, e, 4,75 nas confessionais. Percebe-se que são indicadores "fortes" pois grande parte das ações são voltadas para a comunidade, o que proporciona visibilidade da marca, e pode ser visualizado por meio do desvio padrão que apresentou uma variação muito pequena entre os indicadores. Por meio dos Quadros 10 e 11, pode-se verificar os 19 (dezenove) indicadores referentes ao constructo "gestão" sub-constructo equilíbrio econômico financeiro.

\begin{tabular}{|c|c|c|c|c|c|c|c|c|}
\hline & & & & & NSTITUIÇÕ & ES & & \\
\hline & & INDICADORES & DESCRIÇÃO & $\begin{array}{l}\text { ACAFE } \\
\text { MÉDIA }\end{array}$ & $\frac{\text { COMUNG }}{\text { MÉDIA }}$ & \begin{tabular}{|c|} 
CONFEC \\
MÉDIA
\end{tabular} & GERAL & PADRÃO \\
\hline \multirow{10}{*}{ 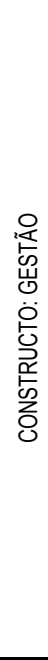 } & \multirow{10}{*}{ 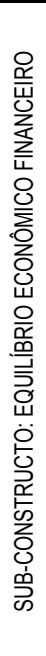 } & $\begin{array}{l}\text { Comprometimento da receita } \\
\text { com folha de pagamento }\end{array}$ & $\begin{array}{c}\text { \% de Gasto com folha de pagamento } \\
\text { (salários e encargos) em relação a } \\
\text { receita total }\end{array}$ & 5,0 & 5,0 & 4,5 & 4,8 & 0,4157 \\
\hline & & Ociosidade de créditos & $\begin{array}{l}\text { \% de créditos não matriculados em } \\
\text { relação ao total de créditos ofertados }\end{array}$ & 5,0 & 5,0 & 4,25 & 4,8 & 0,4714 \\
\hline & & Grau de endividamento & $\%$ de dívidas contraidas por período & 4,7 & 4,5 & 4,75 & 4,6 & 0,4714 \\
\hline & & Redução de despesas gerais & $\begin{array}{l}\text { \% de redução de despesas gerais } \\
\text { em relação a receita total }\end{array}$ & 4,7 & 4,5 & 4,25 & 4,5 & 0,4969 \\
\hline & & Resultado operacional & $\begin{array}{c}\text { Receita operacional menos Custo } \\
\text { operacional }\end{array}$ & 5,0 & 5,0 & 4,75 & 4,9 & 0,3143 \\
\hline & & Capacidade de investimentos & $\begin{array}{l}\text { \% recursos financeiros investidos } \\
\text { em relação a receita total }\end{array}$ & 4,3 & 5,0 & 4,75 & 4,7 & 0,4714 \\
\hline & & Taxa de inadimplência & $\begin{array}{l}\text { \% de inadimplência em relação a } \\
\text { receita total bruta }\end{array}$ & 4,7 & 4,0 & 4,5 & 4,4 & 0,6849 \\
\hline & & Horas docentes & $\begin{array}{l}\text { \% de redução de horas docentes em } \\
\text { relação ao total de horas }\end{array}$ & 5,0 & 4,5 & 3,75 & 4,4 & 0,9428 \\
\hline & & $\begin{array}{c}\text { Margem de contribuição por } \\
\text { cursos }\end{array}$ & $\begin{array}{c}\text { Receita total menos cuto variável } \\
\text { dos cursos em relação a receita total }\end{array}$ & 5,0 & 4,5 & 4,5 & 4,7 & 0,4714 \\
\hline & & Receita realizada no período & $\begin{array}{l}\text { Incremento da receita realizada no } \\
\text { período }\end{array}$ & 4,7 & 5,0 & 4,75 & 4,8 & 0,4157 \\
\hline
\end{tabular}

Quadro 10 Indicadores gestão: equilíbrio econômico financeiro (i) Fonte: Autor 
É possível verificar no Quadro 10 que, dentre os 10 (dez) primeiros indicadores, todos obtiveram uma média considerada importante por todos os respondentes, sendo que a menor média geral é de 4,4. No sub-constructo analisado, a menor média foi obtida nas IES confessionais, embora não se verifica uma diferença significativa entre os 3 (três) segmentos pesquisados. O Quadro 11 apresenta os demais 9 (nove) indicadores que compõem o constructo "gestão".

\begin{tabular}{|c|c|c|c|c|c|c|c|c|}
\hline & & & & & NSTITUIÇÕ & ES & & \\
\hline & & INDICADORES & DESCRIÇÃO & \begin{tabular}{|l|} 
ACAFE \\
MÉDIA \\
\end{tabular} & $\frac{\text { COMUNG }}{\text { MÉDIA }}$ & \begin{tabular}{|c|} 
CONFEC \\
MÉDIA
\end{tabular} & $\begin{array}{l}\text { MEDIA } \\
\text { GERAL }\end{array}$ & PADRÃO \\
\hline \multirow{9}{*}{ 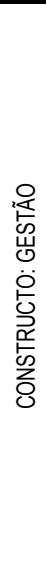 } & \multirow{9}{*}{ 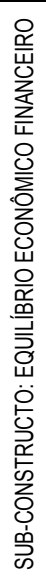 } & Resultado operacional & $\begin{array}{c}\text { Receita operacional menos Custo } \\
\text { operacional }\end{array}$ & 5,0 & 5,0 & 4,75 & 4,9 & 0,3143 \\
\hline & & Lucro Líquido & $\begin{array}{l}\text { Lucro operacional menos resultados } \\
\text { não operacionais e despesas } \\
\text { financeiras }\end{array}$ & 5,0 & 5,0 & 4,75 & 4,9 & 0,3143 \\
\hline & & EVA & $\begin{array}{c}\text { Média da performance que expressa } \\
\text { a criação ou destruição de valor ao } \\
\text { acionista }\end{array}$ & 3,0 & 3,5 & 3,5 & 3,3 & 1,5635 \\
\hline & & $\mathrm{ROI}$ & $\begin{array}{c}\% \text { de retorno sobre os investimentos } \\
\text { totais }\end{array}$ & 4,7 & 4,5 & 4,75 & 4,6 & 0,4714 \\
\hline & & EBITDA & $\begin{array}{l}\text { \% de lucro antes dos juros, IR, } \\
\text { depreciação e amortizações }\end{array}$ & 4,7 & 4,5 & 4,75 & 4,6 & 0,4714 \\
\hline & & Margem líquida & $\begin{array}{l}\text { Receita total menos custos variáveis } \\
\text { e fixos, em relação a receita total }\end{array}$ & 5,0 & 4,5 & 4,75 & 4,8 & 0,4157 \\
\hline & & $\begin{array}{l}\text { Resultado antes dos } \\
\text { impostos }\end{array}$ & $\begin{array}{c}\text { Lucro bruto menos os custos } \\
\text { operacionais, despesas gerais e } \\
\text { administrativas }\end{array}$ & 5,0 & 4,5 & 4,75 & 4,8 & 0,4157 \\
\hline & & Faturamento por curso & $\begin{array}{l}\text { Receita bruta por curso segmentada } \\
\text { por componente curricular }\end{array}$ & 5,0 & 4,5 & 4,5 & 4,7 & 0,4714 \\
\hline & & Liquidez Corrente & $\%$ de liquidez corrente & 5,0 & 4,0 & 4,75 & 4,6 & 0,6667 \\
\hline
\end{tabular}

Quadro 11 Indicadores gestão: equilíbrio econômico financeiro (ii)

Fonte: Autor

Nota-se que os nove indicadores constantes no Quadro 11, também foram bem avaliados pelos respondentes. Destaca-se que, de modo geral, dentre os 19 (dezenove) indicadores, somente o indicador "EVA" ficou com média inferior a 4, obtendo média geral 3,3, com média 3,0 nas IES do sistema ACAFE, 3,5 no COMUNG e igual média nas confessionais. Sendo assim, este indicador será excluído do painel, visto que apresenta média inferior à nota de corte que é de 3,5. Esse mesmo indicador apresentou desvio padrão acima de um. Os demais indicadores foram avaliados como importantes por todas as IES que participaram da pesquisa. Na sequência, pode-se verificar por meio dos Quadros 12 e 13, indicadores de gestão, sub-constructo desenvolvimento humano (i) e (ii), que totalizam 17 (dezessete) indicador, os quais são fundamentais para qualquer empresa. 


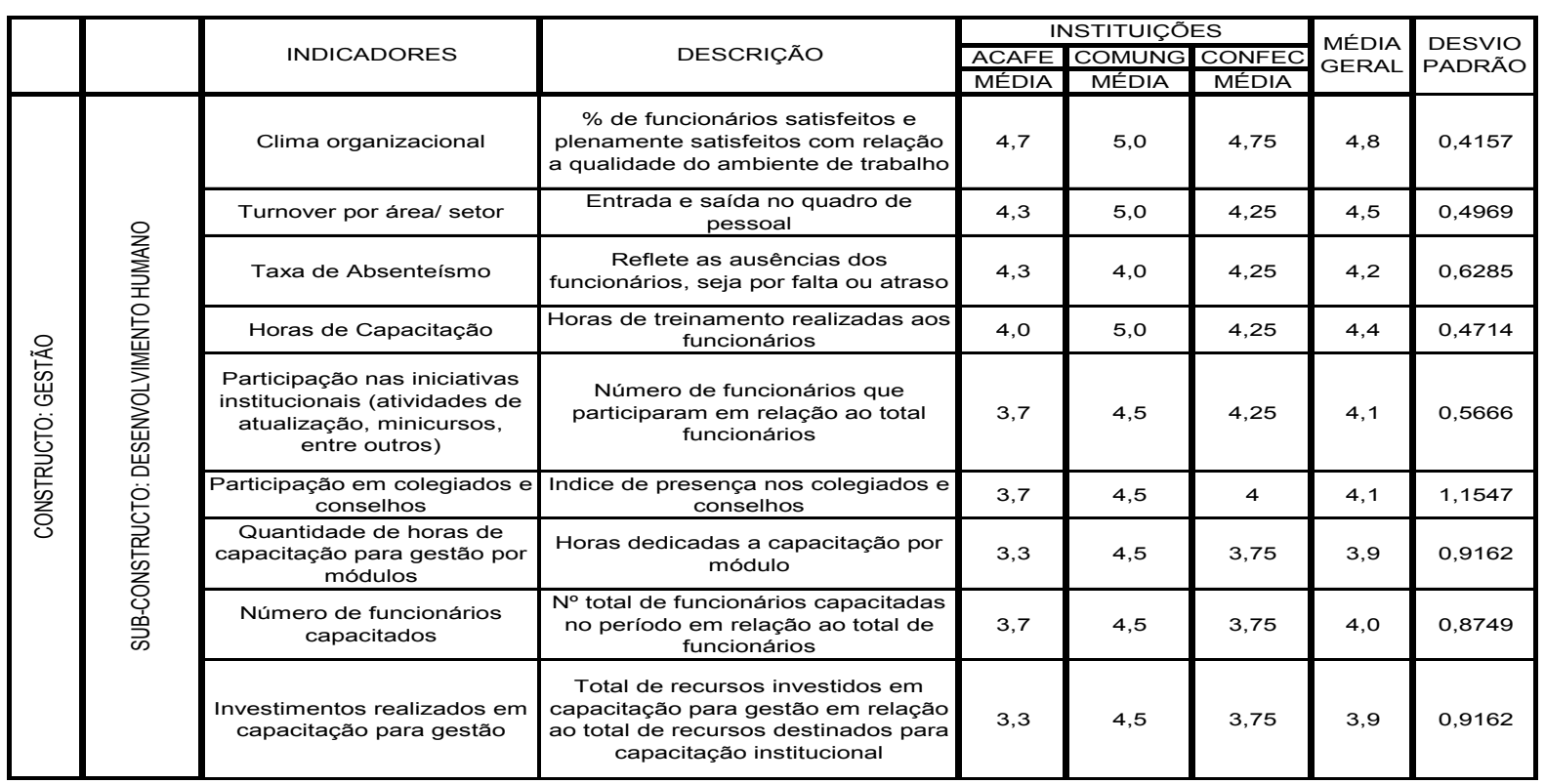

Quadro 12 Indicadores gestão: desenvolvimento humano (i)

Fonte: Autor

Efetuando-se a análise do sub-constructo desenvolvimento humano, Quadro 12, verifica-se que as IES do sistema ACAFE obtiveram a menor média na maior parte dos indicadores avaliados, tendo 5 (cinco) indicadores com média abaixo de 4,0. O segmento que apresentou a maior média foram as IES associadas ao COMUNG, considerando todos os indicadores selecionados para análise como importante e ou muito importante.

O indicador "clima organizacional" foi considerado o indicador mais importante por parte de todos os respondentes. Dentre os 17 (dezessete) indicadores de gestão: desenvolvimento humano (i) e (ii), 3 (três) obtiveram média inferior a 4,0 nos segmentos ACAFE e confessionais ("quantidade de horas de capacitação para gestão por módulos", "número de funcionários capacitados", e, "investimentos realizados em capacitação para docentes"), porém acima da nota de corte de 3,5, mantendo-se todos os indicadores no painel.

Por meio do Quadro 13, visualiza-se a continuidade do painel de indicadores selecionados para o constructo gestão, sub-constructo desenvolvimento humano (ii). 


\begin{tabular}{|c|c|c|c|c|c|c|c|c|}
\hline & & & & & VSTITUIÇÕ & ES & & \\
\hline & & INDICADORES & DESCRIÇÃO & $\begin{array}{l}\text { ACAFE } \\
\text { MÉDIA }\end{array}$ & $\frac{\text { COMUNG }}{\text { MÉDIA }}$ & \begin{tabular}{|c|} 
CONFEC \\
MÉDIA
\end{tabular} & $\begin{array}{l}\text { MEDIA } \\
\text { GERAL }\end{array}$ & PADRÃO \\
\hline \multirow{8}{*}{ 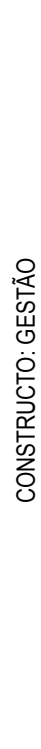 } & \multirow{8}{*}{ 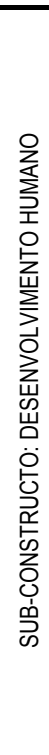 } & $\begin{array}{c}\text { Índice de satisfação do corpo } \\
\text { Docente, Técnico- } \\
\text { Administrativo, Gestores e } \\
\text { Discentes }\end{array}$ & \% de Satisfação docente & 4,3 & 4,5 & 4,75 & 4,5 & 0,4969 \\
\hline & & $\begin{array}{c}\text { Índice de satisfação do corpo } \\
\text { Docente, Técnico- } \\
\text { Administrativo, Gestores e } \\
\text { Discentes }\end{array}$ & $\begin{array}{c}\text { \% de Satisfação de técnico } \\
\text { administrativo }\end{array}$ & 4,3 & 4,5 & 4,75 & 4,5 & 0,4969 \\
\hline & & $\begin{array}{c}\text { Índice de satisfação do corpo } \\
\text { Docente, Técnico- } \\
\text { Administrativo, Gestores e } \\
\text { Discentes }\end{array}$ & $\begin{array}{l}\text { \% de Satisfação do coordenador de } \\
\text { curso }\end{array}$ & 4,3 & 4,5 & 4,75 & 4,5 & 0,4969 \\
\hline & & $\begin{array}{c}\text { Índice de satisfação do corpo } \\
\text { Docente, Técnico- } \\
\text { Administrativo, Gestores e } \\
\text { Discentes }\end{array}$ & \% de Satisfação discente & 4,7 & 5,0 & 4,75 & 4,8 & 0,4157 \\
\hline & & $\begin{array}{l}\text { Índice de satisfação dos } \\
\text { usuários e gestores com os } \\
\text { sistemas de informação }\end{array}$ & $\begin{array}{l}\text { \% de satisfação dos usuários e } \\
\text { gestores com os sistemas de } \\
\text { informação }\end{array}$ & 4,7 & 5,0 & 4,25 & 4,6 & 0,4969 \\
\hline & & Horas extras trabalhadas & $\begin{array}{c}\text { \% de horas extras trabalhadas por } \\
\text { total de funcionários }\end{array}$ & 4,0 & 4,5 & 4,25 & 4,3 & 0,6285 \\
\hline & & $\begin{array}{l}\text { Índice de frequência de } \\
\text { acidentes de trabalho }\end{array}$ & $\begin{array}{c}\% \text { de acidentes de trabalho por total } \\
\text { de funcionários }\end{array}$ & 4,3 & 4,5 & 4,5 & 4,4 & 0,4969 \\
\hline & & $\begin{array}{l}\mathrm{N}^{\circ} \text { de funcionários em } \\
\text { afastamento médico }\end{array}$ & $\begin{array}{l}\text { \% de funcionários em afatamento } \\
\text { médico por total de funcionários }\end{array}$ & 4,3 & 4,5 & 3,75 & 4,2 & 0,8749 \\
\hline
\end{tabular}

Quadro 13 Indicadores gestão: desenvolvimento humano (ii)

Fonte: Autor

Por meio do Quadro 13, verifica-se que, de modo geral, dentre os dezessete indicadores do constructo "gestão", apenas o indicador "participação em colegiados e conselhos" apresentou desvio padrão superior a um, sendo que os demais indicadores não apresentaram grandes distorções entre os respondentes. Na sequência, ainda no constructo gestão, evidencia-se no Quadro 14, o sub-constructo instrumentos de avaliação com a sugestão de 4 (quatro) indicadores.

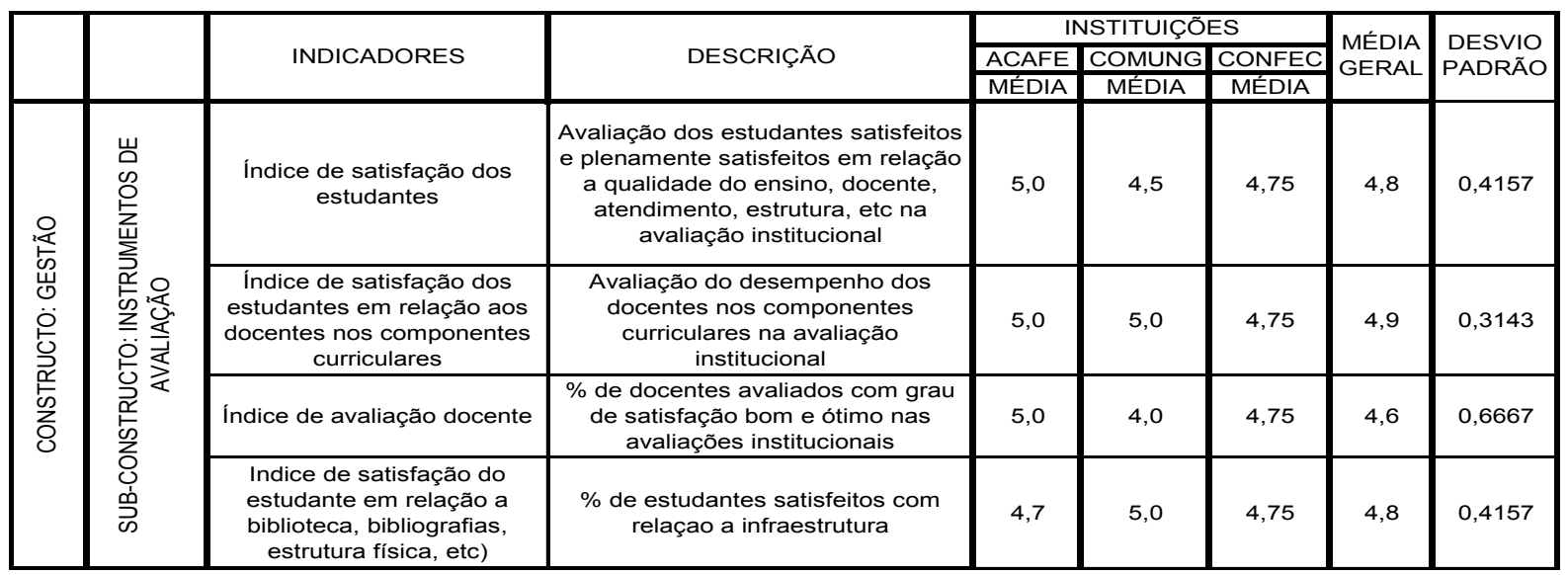

Quadro 14 Indicadores gestão: instrumentos de avaliação Fonte: Autor 
Nota-se no Quadro 14, que os indicadores foram considerados muito importantes pelos respondentes. As médias ficaram muito próximas, se comparado cada segmento individualmente, confirmando-se pelo desvio padrão. As IES do sistema ACAFE contribuíram para aumentar a média dos indicadores avaliados. A menor média geral refere-se ao indicador "índice de avaliação docente", que embora obteve média 5,0 na ACAFE e 4,75 entre as IES confessionais, a média de 4,0 nas IES do COMUNG interferiu de forma significativa, baixando a média geral para 4,6. Os demais indicadores ficaram com médias semelhantes entre as IES respondentes. $\mathrm{Na}$ dimensão gestão, sub-eixo procedimentos acadêmicos/processos internos, Quadro 15, elencou-se 4 (quatro) indicadores.

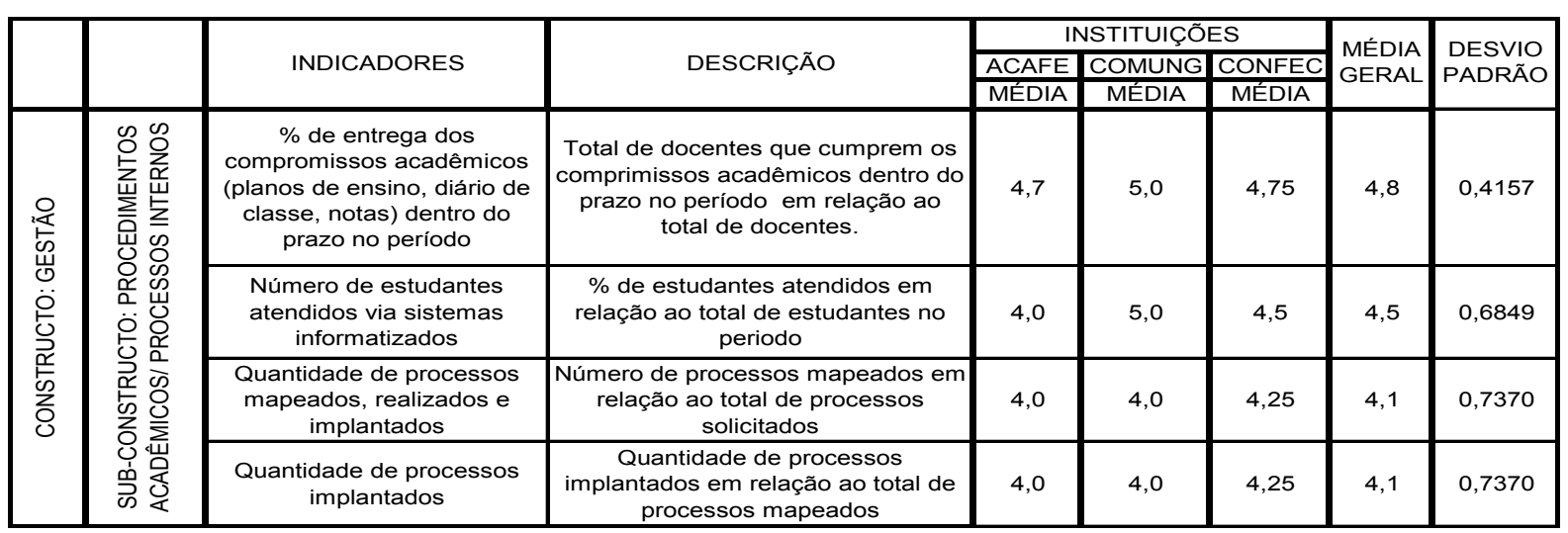

Quadro 3 Indicadores gestão: procedimentos acadêmicos/processos internos Fonte: Autor

Os indicadores do Quadro 15 são considerados importantes. Dentre os 4 (quatro) indicadores, 2 (dois) (quantidade de processos mapeados, realizados e implantados, e, quantidade de processos implantados) obtiveram média geral de 4,1 . O indicador “\% de entrega dos compromissos acadêmicos (planos de ensino, diário de classe, notas) dentro do prazo no período" foi considerado como importante e muito importante, pelos respondentes, obtendo-se a maior média geral 4,8 e menor desvio padrão.

O indicador "número de estudantes atendidos via sistemas informatizados" obteve sua menor média nas IES do sistema $\operatorname{ACAFE~}(4,0)$, 4,5 nas IES confessionais e 5,0 no COMUNG. O modelo de indicadores de avaliação organizacional, no constructo gestão, também considerou o sub-constructo conhecimento e inovação, conforme se verifica no Quadro 16. 


\begin{tabular}{|c|c|c|c|c|c|c|c|c|}
\hline & & \multirow[b]{2}{*}{ INDICADORES } & \multirow[b]{2}{*}{ DESCRIÇÃO } & \multicolumn{3}{|c|}{ INSTITUIÇÕES } & \multirow{2}{*}{$\begin{array}{l}\text { MÉDIA } \\
\text { GERAL }\end{array}$} & \multirow{2}{*}{$\begin{array}{l}\text { DESVIO } \\
\text { PADRÃO }\end{array}$} \\
\hline & & & & $\frac{\text { ACAFE }}{\text { MÉDIA }}$ & $\frac{\text { COMUNG }}{\text { MÉDIA }}$ & \begin{tabular}{|c|} 
CONFEC \\
MÉDIA
\end{tabular} & & \\
\hline \multirow{6}{*}{ 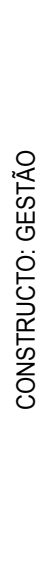 } & \multirow{6}{*}{ 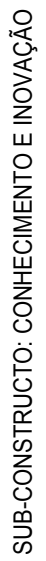 } & $\begin{array}{l}\text { Quantidade de acessos aos } \\
\text { produtos ofertados }\end{array}$ & $\begin{array}{c}\text { Número de acessos aos novos } \\
\text { produtos em relação ao total de } \\
\text { produtos ofertados }\end{array}$ & 4,7 & 5,0 & 4,25 & 4,6 & 0,6849 \\
\hline & & $\begin{array}{l}\text { Contratos de prestação de } \\
\text { serviço }\end{array}$ & $\begin{array}{l}\text { Número de contratos de prestação } \\
\text { de serviços efetivados no período }\end{array}$ & 4,0 & 4,5 & 4 & 4,2 & 0,7370 \\
\hline & & $\begin{array}{c}\text { Número de projetos } \\
\text { executados em relação ao } \\
\text { número de projetos enviados } \\
\text { para os orgãos de fomento }\end{array}$ & $\begin{array}{l}\text { Número de projetos aprovados em } \\
\text { relação ao total de projetos enviados }\end{array}$ & 4,7 & 4,0 & 4,25 & 4,3 & 0,8165 \\
\hline & & $\begin{array}{l}\text { Quantidade de empresas } \\
\text { incubadas }\end{array}$ & $\begin{array}{c}\text { Número de empresas incubadas em } \\
\text { relação ao total de empresas } \\
\text { cadastradas }\end{array}$ & 2,7 & 4,0 & 4 & 3,6 & 0,9558 \\
\hline & & $N^{\circ}$ de depósitos de patentes & $\begin{array}{l}\text { Número de depósitos de patentes } \\
\text { encaminhadas }\end{array}$ & 3,7 & 4,0 & 4,25 & 4,0 & 1,0541 \\
\hline & & $\mathrm{N}^{\circ}$ projetos executados & $\begin{array}{c}\text { Número de projetos executados em } \\
\text { relação ao total de projetos } \\
\text { aprovados }\end{array}$ & 3,0 & 4,0 & 3,5 & 3,5 & 0,9558 \\
\hline
\end{tabular}

Quadro 4 Indicadores gestão: Conhecimento e inovação Fonte: Autor

Por meio do Quadro 16, verifica-se que dentre os 6 (seis) indicadores avaliados no modelo, 2 (dois) obtiveram média inferior a 4,0, ou seja: 3,6 e 3,5 para os indicadores "quantidade de empresas incubadas" e "número de projetos executados". A principal disparidade que se verifica entre os respondentes, refere-se ao indicador "quantidade de empresas incubadas" que foi considerado pouco importante pelas IES do sistema ACAFE, com média 2,7, enquanto este indicador foi considerado importante pelos demais respondentes, atingindo média 4,0 .

O indicador "número de projetos executados" obteve média 3,0 entre as IES do sistema ACAFE e 3,5 entre as confessionais, enquanto as IES pertencentes ao COMUNG ficaram com média 4,0. Os demais indicadores tiveram pequenas avaliações nas médias entre os 3 segmentos pesquisados. Com relação ao desvio padrão, a maior distorção ocorreu no indicador "número de depósito de patentes", que apresentou índice superior a um.

Ainda dentro do constructo gestão, incluiu-se o sub-constructo infraestrutura, conforme se verifica no Quadro 17. 


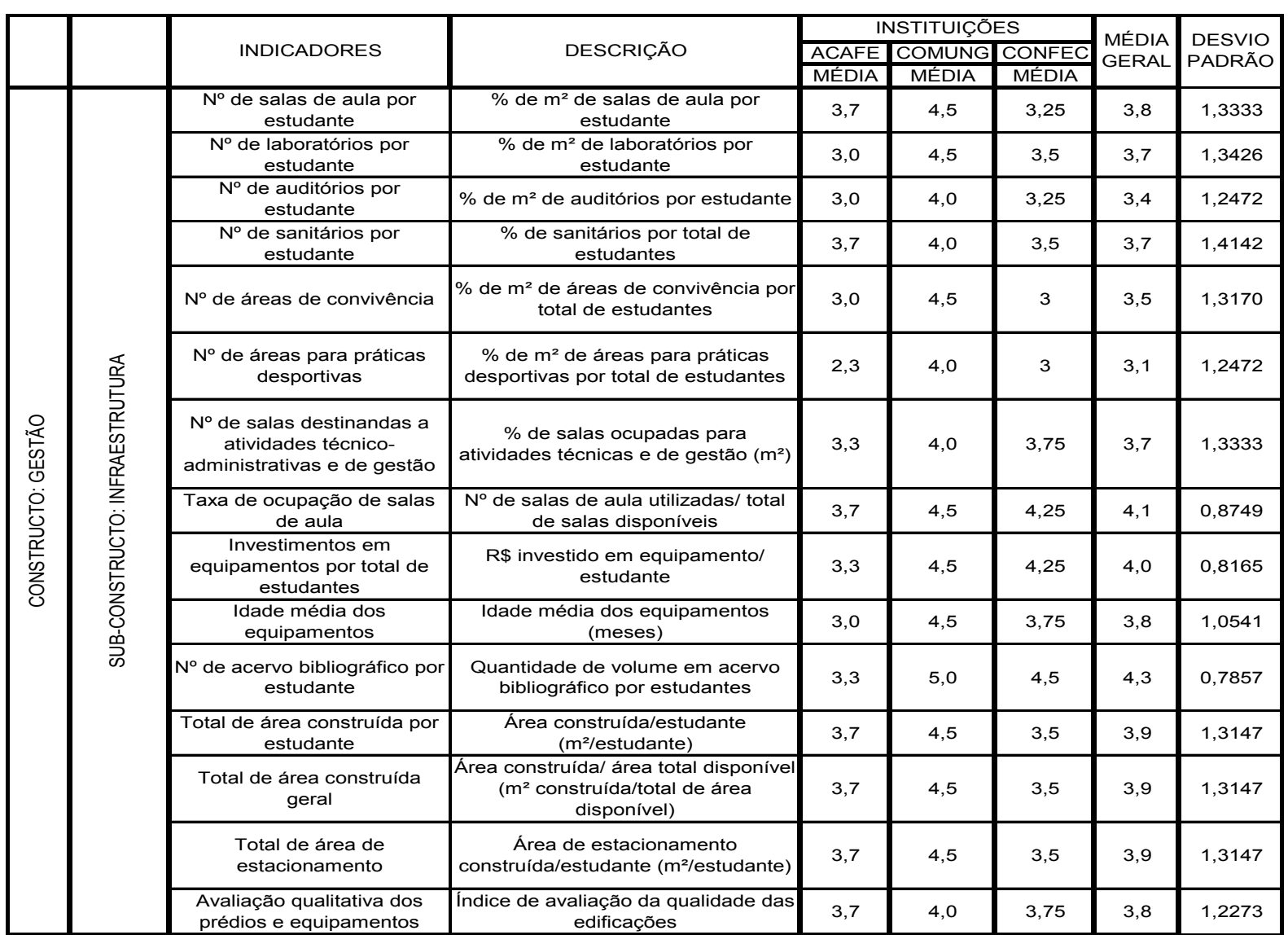

Quadro 17 Indicadores gestão: infraestrutura Fonte: Autor

Conforme apresentado no Quadro 17, dentre todos os constructos e sub-constructos propostos para o painel de avaliação de desempenho organizacional, este sub-eixo foi o que obteve a menor média geral, tendo apenas 3 (três) indicadores com média geral 4,0 ou superior. As IES do sistema ACAFE, entre os três segmentos, obtiveram a menor média, não considerando nenhum dos indicadores como importantes.

Os indicadores pertencentes ao sub-constructo infraestrutura também foram os que apresentaram maior diferença entre os três segmentos. Por meio do desvio padrão, verifica-se que dos quinze indicadores sugeridos no painel, apenas três apresentaram índice inferior a um, o que confirma uma maior disparidade de peso entre os indicadores.

Nas avaliações externas, também de avalia a infraestrutura, além do acervo bibliográfico, repercutindo na nota do Conceito de Curso (CC), dentre outras avaliações. Como exemplo, cita-se a recomendação de ter na biblioteca no mínimo um livro das referências básicas a cada dez estudantes, o que reforça que este indicador precisa ser cuidado pelas IES. 
Por meio do Quadro 17 verifica-se ainda que entre os respondentes, as IES do sistema ACAFE consideraram o indicador "número de acervo bibliográfico por estudante" pouco importante, com média 3,3. Os respondentes do COMUNG consideraram esse indicador como muito importante, obtendo média 5,0, enquanto as IES confessionais atribuíram média 4,5. As IES pertencentes ao COMUNG, foram as que contribuíram para elevar a média geral, pois entre os indicadores propostos, todos foram avaliados acima da média, comparando-se com as IES pertencentes ao sistema ACAFE e às confessionais.

\section{DISCUSSÃO DOS RESULTADOS E CONSIDERAÇÕES FINAIS}

A avaliação de desempenho é fundamental para todas as IES, independente de ser pública, comunitária ou privada. O MEC recomenda que o PDI estabeleça objetivos, metas e padrões de qualidade, contendo um resumo dos principais indicadores de desempenho, possibilitando comparações entre a situação atual e o futuro, tendo em vista que a validade é de 5 anos. Sugere dimensões em três níveis: (i) Organização institucional e pedagógica; (ii) Corpo docente, (iii) Instalações.

O Sistema Nacional de Avaliação da Educação Superior - SINAES avalia todos os aspectos que giram em torno das dimensões: ensino, pesquisa, extensão, responsabilidade social, desempenho do aluno, gestão da instituição, corpo docente, instalações e vários outros aspectos, reforçando a necessidade das IES efetuarem sua autoavaliação.

Esses procedimentos pressionam as IES a implantarem indicadores de desempenho objetivando a gestão, pois ações preventivas podem auxiliar na melhoria do ranqueamento da IES. Embora os organismos governamentais enfatizem que o ENADE, CPC, dentre outros, não se destinam a ranquear as IES, utilizam esses conceitos para fechamento de cursos e/ou até mesmo Instituições de Ensino.

A proposta de um painel de indicadores de desempenho apresentado neste estudo, iniciou pela definição de 4 (quatro) constructos e 14 (quatorze) sub-constructos. O conjunto e ou/painel de indicadores propostos, inseridos em cada sub-constructo e constructo, procura contemplar todos os indicadores necessários para atender às avaliações interna e externas. Pode ser utilizado para avaliar a qualidade acadêmica referente ao ensino, pesquisa, extensão e gestão.

Cada um dos constructos e sub-constructos, por meio dos indicadores propostos, possuem a missão de gerar informações relevantes para tomada de decisões, iniciando pela 
qualidade do ensino. O ranqueamento que ocorre por meio das avaliações externas, influencia diretamente na prospecção de estudantes, tendo em vista a concorrência acirrada, principalmente para as IES comunitárias, que se encontram entre as IES públicas, que não cobram mensalidades na oferta do ensino, e as IES privadas, que possuem uma eficiência maior na gestão de custos, pode ofertar o ensino com mensalidades menores.

Os indicadores foram submetidos para avaliação junto a gestores de IES comunitárias, por meio de questionário, em que os respondentes atribuíram nota de $1 \mathrm{a} 5$, de acordo com o grau de importância. Estabeleceu-se como nota de corte os indicadores com média inferior a 3,5. Dos 122 indicadores propostos, permaneceram 118 indicadores.

Os indicadores excluídos do painel foram: (I) Número de cursos efetivados, no constructo ensino, sub-constructo pós-graduação stricto sensu; (II) Indicador EVA, no subconstructo equilíbrio econômico financeiro, no constructo gestão; (III) Ainda no constructo gestão, sub-constructo infraestrutura, dois indicadores obtiveram média inferior a 3,5, e foram excluídos do painel, ou seja: o indicador número de auditório por estudantes e número de áreas para práticas esportivas.

Os indicadores EVA, ROI e EBITDA, inseridos na dimensão gestão, sub-eixo equilíbrio econômico financeiro, são utilizados fortemente em organizações que buscam o lucro. No entanto, esses indicadores podem ser utilizados também por IES comunitárias, sendo parâmetro de comparabilidade, pois o superávit gerado nas IES comunitárias, são investidos na melhoria da qualidade acadêmica, pesquisa, extensão e infraestrutura.

Entre os constructos propostos, e seus respectivos sub-constructos, gestão: infraestrutura, foi o que apresentou um maior número de indicadores com média próximo da nota de corte, embora necessária para oferta do ensino, pesquisa e extensão, tripé de uma Universidade.

A principal contribuição do modelo proposto, é um rol de indicadores agrupados em dimensões que são utilizadas em avaliações externas, que podem ser utilizados para avaliação interna de forma isolada ou atrelado ao planejamento estratégico, inserindo-se os indicadores necessários de acordo com os projetos estratégicos. Ressalta-se que o painel de indicadores proposto, embora sugerido para as IES comunitárias, poderá ser utilizado para todos os modelos de IES, pois contém vários indicadores financeiros relacionados ao retorno do investimento e rentabilidade. 


\section{REFERÊNCIAS}

BANKER, R., G. Et al. An empirical investigation of an incentive plan that included nonfinancial performance measures. The Accounting Review 75 (1): 65-92. 2000.

BRASIL. Instituto Nacional de Estudos e Pesquisas Educacionais Anísio Teixeira - INEP. Censo da educação superior: 2011 - resumo técnico. Brasília, 2013. Disponível em: http://download.inep.gov.br/educacao_superior/censo_superior/resumo_tecnico/resumo_tecni co_censo_educacao_superior_2011.pdf. Acesso em: 02/07/2013.

BRASIL. Ministério das Relações Exteriores - ITAMARATY. Denominação das Instituições de Ensino Superior -IES. Disponível em:

http://www.dce.mre.gov.br/nomenclatura_cursos.html. Acesso em: 02/07/2013.

BRASIL. Lei de diretrizes e bases da educação nacional. Lei no 9.394, de 20 de dezembro de 1996. Estabelece as diretrizes e bases da educação nacional - LDB. Disponível em: http://www.planalto.gov.br/ccivil_03/leis/19394.htm. Acesso em: 02/07/2013.

CARVALHO, M. H. Reengenharia comportamental aplicada as Instituições de Ensino Superior. In: FINGER, A.P. (Org.). Gestão de universidades: novas abordagens. Curitiba: Champagnat, 1997.

COSTA, R. N. Balancedscorecard: um aplicativo para ser usado em sala de aula. 2006. 128f. Dissertação de Mestrado em Ciências Contábeis do Programa de Pós-Graduação em Ciências Contábeis da Universidade Regional de Blumenau. Blumenau - SC, 2006.

DAVIS, Mark M.; AQUILINO, Nicholas J.; CHASE, Richard B. Fundamentos da administração da produção. Porto alegre: Bookmann, 2001.

DÍAZ, Mario de Miguel. Aulorregulacîon y toma de decisiones em las instituciones universitárias. Educación, n. 308, p. 63-80, 1995.

FISCHMANN, A.; ZILBER, M.. Utilização de indicadores de desempenho para a tomada de decisões estratégicas: um sistema de controle. Revista de Administração Mackenzie, América do Norte, Ano 1, n.1, p. 9-25, mai. 2000.

HOLANDA, Fernanda Marques de Almeida. Indicadores de desempenho: uma analise nas empresas de construção civil do município de João Pessoa - PB. Dissertação de Mestrado Programa Multi-institucional e Inter-Regional de Pós Graduação em Ciências Contábeis, da Universidade de Brasília, da Universidade Federal da Paraíba, da Universidade Federal de Pernambuco e da Universidade Federal do Rio Grande do Norte.

INEP (INSTITUTO NACIONAL DE ESTUDOS E PESQUISAS EDUCACIONAIS ANÍSIO TEIXEIRA). Sinopse da Educação Superior. 2010. Disponível em:

<http://www.inep.gov.br/superior/censosuperior/sinopse/ >. Acessoem: 23 abril 2013.

LIMA, M. A. Uma proposta do balanced scorecard para a gestão estratégica das universidades Fundacionais de Santa Catarina. 2003. Tese de Doutorado em Engenharia 
de Produção do Pós-Graduação em Engenharia de Produção. Universidade Federal de Santa Catarina. Florianópolis, 2003.

MARTINS, C. B. Uma reforma necessária. Educação e Sociedade, Campinas, v. 27, n. 96 Especial, p. 1001-1020, out. 2006.

MORISSETE, R. Toward a theory of information choices in organizations: an integrative approach. 1977. Thesis (Ph.D. at Accounting) - University of Waterloo, Waterloo, 1977.

OLIVEIRA, D.P.R. Planejamento estratégico: Conceitos, metodologias e práticas. 13. Ed. São Paulo: Atlas, 1999.

PESSOA, M. N. M. Gestão das Universidades Federais Brasileiras - Um Modelo Fundamentado No Balanced Scorecard. Tese de doutorado da Universidade Feral de Santa Catarina - UFSC, 2000.

RIVERO, J. L. A.; LÓPes, J.G. El processo de planificación estratégica enlos Universidades. Desencuentros y retos para elmajoramiento de sucalidad. Revista GUAL. V. 5. N. 2, p. 72-97, Ago 2012.

RODRIGUES, L. C. et al. Sistema de informação de marketing (SIM) como vantagem competitiva das instituições de ensino superior. In: COLOSSI, N. et al. A gestão universitária em ambiente de grandes mudanças na américa do sul. Blumenau: Nova Letra, 2002.

RODRIGUES, C. M, C. Proposta de Avaliação Integrada ao Planejamento Anual: um Modelo Para as Ucg's. Tese de Doutorado da Universidade Federal do Rio Grande do Sul UFRGS. Porto Alegre - RS, 2003.

RODRIGUES FILHO, A. L.; OLIVEIRA, L. R. de. Análise de informações para gestão de relacionamento com alunos em instituição de ensino superior. Revista Produto \& Produção. Vol. 12, N. 2, p. 48-68, Jun. 2011. 